\title{
PROLIFERATION OF HISTAMINE AND SEROTONIN IN MAST CELLS OF PATIENTS WITH INFLAMMATORY PERIODONTAL DISEASE IN THE COURSE OF TREATMENT
}

\section{Kamilla Khabibullina? , Yulia Osipova ${ }^{1 凶}$, Natalia Bulkina? Anna Kropotina' , Diana Avedova', Valeriy Konnov ${ }^{3}$}

\author{
${ }^{1}$ Department of Therapeutic Dentistry; Saratov State Medical University, \\ Saratov \\ 2 Department of Dentistry Therapeutic and Periodontology, Pavlov First St. \\ State Medical University of St. Petersburg \\ ${ }^{3}$ Department of Orthopedic Dentistry; Saratov State Medical University, \\ Saratov
}

osipova-sgmu@mail.ru

\begin{abstract}
The purpose of this study was to examine the indicators of cell proliferation, apoptosis, as well as the quantitative features of histamine and serotonin producing gum mast cells in patients with chronic gingivitis and periodontitis through the treatment dynamics. The study has shown that gingivitis is associated with hyperplasia and hyperfunction of the gum mast cells general population producing histamine, as well as with an increase in cell proliferation. Periodontitis revealed an increase in apoptosis, a decrease in periodontal proliferation due to hyperplasia and hyperfunction of the total mast cell population secreting histamine and serotonin.
\end{abstract}

KEYW ORDS - gingivitis, periodontitis, proliferation, apoptosis, cell renewal, mast cells, histamine, serotonin.

\section{INTRODUCTION}

Modern studies [1-8] reveal that the general pathomorphological pattern that determines the course and prognosis of any chronic process, including periodont inflammatory diseases, is due to the intensity of cell renewal processes, which can be employed both for early diagnosis of the disease, and to for developing its forecast. The involvement of mast cells in inflammation regulation and tissues proliferation explains the increased interest that researchers take in studying their role in periodont inflammatory diseases [10-16]. There is still lack of research in terms of studying quantitative features and functional organization of gum mast cells producing histamine and serotonin, if compared with the status of gum epithelial cells renewal in the pathogenesis of periodont inflammatory diseases [9].
Aim of study:

to investigate the cell renewal of gum epithelial cells and the quantitative specifics of gum mast cells producing histamine and serotonin in patients with chronic gingivitis and periodontitis through the treatment dynamics.

\section{MATERIAL AND METHODS}

The study involved 80 patients with chronic catarrhal gingivitis (CCG); 50 patients with mild chronic generalized periodontitis (CGP); the comparison group included 20 patients with intact periodont. All the patients underwent a comprehensive clinical and instrumental examination with their following indicators identified: OHI-s (Green J.C., Vermillion J.R., 1964); PMA (Parma, 1960); $\mathrm{X}$-ray examination of the dentition. The periodontal tissues were studied through gum biopsy specimens (obtained with the patients' consent) during curettage and tooth extraction following orthodontic indications. Mast cells were identified with toluidine blue staining preceded by hydrochloric acid hydrolysis (reaction of hidden metachromasia). To verify histamine and serotonin producing gum mast cells (MC), commercial antibodies to serotonin (Dianova, Gamburg, Germany, 1:100) and histamine (Sigma, St. Louis, USA, titer 1:100) were used as primary antibodies. Monoclonal murine antibodies were used to the Ki-67 proliferating cell marker (Sigma, St. Louis, USA, titer 1:200). To identify apoptotic nuclei, the method of impregnation was used. The number of expressing cells was counted in 30 fields of view, and at the indicated magnigication, the numerical data was counted as per $1 \mathrm{~mm}^{2}$ using the Video Test-Morphology 4.0 application morphometric software package.

The obtained outcomes were processed using Statistica version 8.0. The verification of quantitative numerical indicators for compliance with the normal distribution was performed using the Shapiro-Francia criterion. To test the hypotheses about the difference in the average values of normally distributed characteristics, Student and Fisher criteria were used, to identify differences in other values, the Mann-Whitney, Wilcoxon rank criteria were used. 


\section{RESULTS AND DISCUSSION}

The patients with gingivitis and periodontitis complained of bleeding gums, slight soreness, and halitosis. An objective examination determined hyperemia, swelling, and bleeding gums. The level of individual hygiene and inflammation in cases of gingivitis (OHI-s 2.94 \pm 0.021 ); PMA (35.2 $\pm 1.2 \%)$ and periodontitis (OHI-s $3.25 \pm 0.013)$; PMA (42.2 $\pm 1.7 \%$ ) revealed no significant differences. Morphological and immunohistochemical studies revealed that the intact periodont had the general MC population indicators (9.2 \pm 0.5$)$, MC-histamine (7.6 \pm 0.5$),$ MC-serotonin $(5.4 \pm 0,54)$. Gingivitis is associated with hyperplasia of the general population of gum MC $(11.8 \pm 0.7)$ and histamine producing $\mathrm{MC}(11.7 \pm 0.6)$. The development of CGP featured an increase in the quantitative density of the total MC population $(14.5 \pm 0.6)$ with hyperplasia of $\mathrm{MC}$ cells producing both histamine $(14.2 \pm 0.6)$ and serotonin (13.2 \pm 0.6$)$. An electron microscopy study revealed signs of varying intensity MC degranulation, which is equivalent to an increase in their functional activity in both gingivitis and periodontitis. There was a direct correlation observed between the quantitative density of gum MC producing histamine and the PMA index for gingivitis and periodontitis $(r=0.64$ and $r=0.69$, respectively), between the number of serotonin producing $\mathrm{MC}$ and PMA in CP $(r=0.72)$.

The immunohistochemical study of the gums in healthy people in the periodontal epithelium revealed low values of proliferative $(\mathrm{Ki}-679.53 \pm 0.19)$ and apoptotic activity (Iapt $0.38 \pm 0.04$ ). In HCG cases, the proliferation and apoptosis indices do not change significantly (Ki-67 9.53 \pm 0.19 ; Iapt $0.38 \pm 0.04$ ), which pointed at high compensatory capacity of the epithelium at this stage of the disease. CGP was found to have an expression increase $(\mathrm{Ki}-67=28.88 \pm 1.42)$ and a low apoptosis rate (lapt $0.54 \pm 0.03$ ). These results suggest that the basis of HCG and CGP morphogenesis belongs to disturbed renewal of epithelial cells. Catarrhal gingivitis is characterized by activated proliferation, while chronic periodontitis - by an increase in apoptosis activity with a decrease in cell proliferation. The dissociation between the proliferation and apopotosis activity in patients with CGP causes low cell renewal and an increase in degenerative processes in periodontal tissues. Hyperplasia of serotonin-producing mast cells leads to reduced gum regeneration. For instance, in case of CGP, hyperplasia of serotonin-producing gum MC is accompanied by an increase in apoptotic activity and a decrease in proliferation in the marginal gum epithelium, which is confirmed by a direct correlation between the number of $\mathrm{MC}$ with apoptosis indices $(\mathrm{r}=0.75)$, and an invert correlation with Ki-67 $(\mathrm{r}=-0.57)$.
The conservative therapy led to restored periodontal structure in the patients involved. The results of morphofunctional studies prove that restoration of the structural and functional features of the periodont is achieved only a month after therapy. Patients with CCG, 14 days into the treatment revealed normalized quantitative density of the general population of periodontal MC $(8.1 \pm 0.3)$, MC-serotonin $(5.1 \pm 0.5)$, MC-histamine $(7.9 \pm 0.2)$. In patients with CGP, the number of the total population of gum $\mathrm{MC}$ $(12.5 \pm 0.3)$, and the number of serotonin producing gum MC (9.1 \pm 0.4$)$ remained slightly elevated and improved only a month after the therapy (MC serotonin $5.7 \pm 0.4$ ). In the group of patients with CGP, two weeks after therapy, a significant increase in the $\mathrm{Ki}-67$ index was observed, if compared with the same value before the treatment. The activity of gum epithelial cells apoptosis decreased slightly, not to reach the values observed in the control group, though. One month after treatment, the patients with CGP featured improved cell renewal of gum epithelial cells.

\section{CONCLUSION}

The leading factors in the occurrence and progression of inflammatory periodont diseases include deteriorated oral hygiene, changed neurohumoral regulation of periodont disease associated with mast cell hyperplasia, impaired gum epithelial cell renewal. The results obtained here suggest that chronic gingivitis features activated proliferation, hyperplasia and hyperfunction of the general population of gum mast cells producing histamine. The typical features of mild chronic periodontitis include increased apoptosis activity, decreased cell proliferation due to hyperplasia, and hyperfunction of the total mast cell population secreting histamine and serotonin.

\section{REFERENCES}

1. Gorbacheva I.A., Kirsanov A.I., Orekhova L.YU. The unity of systemic pathogenetic mechanisms in diseases of internal organs associated with generalized periodontitis // Dentistry. - 2004. - No. 1 (30). - P. 3-7 (In Russ.).

2. Nikolaeva E.N., Tsarev V.N. Ermolin D.V. Apoptosis and inflammatory periodontal diseases // Institute of Dentistry. - 2003. - No. 4 (21). - P. 91-93 (In Russ.).

3. Reva I.V, Reva G.V, Yamamoto T. et Al. Regulation of proliferative activity of epithelium // Fundamental research. - 2014. - No. 4 (2). - P. 343-346 (In Russ.).

4. Aкimova S.A., Bulkina N.V., Osipova Yu.L., Ostrovskaya L.Yu., Zyulkina L.A., Vedyaeva A.P., Konnov V.V. Gingival mucosa proliferative activity and epitheliocytes apoptosis indicators in pa- 
tients with rapidly progresing periodontitis // Archiv EuroMedica. 2019. Vol. 9. № 2. P. 130-133.

5. Bulkina N.V., Osipova Yu.L., Guseva O.Yu., Morgunova V.M., Kitaeva V.N., Polosukhina E.N., KonNov V.V. Disturbed cell proliferation and apoptosis in patients with chronic periodontitis against the background of gastroesophageal reflux disease // Archiv EuroMedica. 2019. Vol. 9 № 3. P. 97-100. https://doi.org/10.35630/2199$885 \mathrm{X} / 2019 / 9 / 3.27$

6. Bulkina N.V., Morgunova V.M., Osipova Yu.L., Pronina N.S., Polosukhina E.N., Guseva O.Yu. Kropotina A.Yu., Konnov V.V. Cytokine profile of periodontal pocket contents in estimating the severity and efficiency of treatment offered to patients with refractory periodontitis // Archiv EuroMedica. 2019. Vol. 9. № 2. P. 133-136.

7. Bulkina N.V., Makarova N.I., IVANov P.V., LEBEDEV M.V., ZYUlKina L.A., Shastin E.N., KonNOV V.V. Modern methods of non-invasive correction for disturbed regional blood circulation through physiotherapeutic measures (Literature Review) // Archiv EuroMedica. 2019. Vol. 9. № 2. P. 17-22.

8. Indicators of cell renewal and gum apoptosis in patients with rapidly progressive periodontitis. / Osipova Yu.L., Akimova S.A. Morphology. 2018. Vol. 153. № 3. P. 209 (In Russ.).

9. Indicators of cell renewal and gum apoptosis in patients with rapidly progressive periodontitis. / Yu.L. Osipova, S.A. Akimova / Morphology. - 2018. Vol.153., №3. - P. 209-210. (In Russ.).

10. Osipova Yu.L., Bulkina N.V., Osadchuk M.A., KVETNOY I.M. The role of cell proliferation and apoptosis disorders in the pathogenesis of inflammatory periodontal diseases on the background of gastroesophageal reflux disease // Saratov Journal of Medical Scientific Research. 2013.V. 9. No. 3. P. 449-453 (In Russ.).

11. Osipova Yu.L., Bulkina N.V., Kropotina A.Yu. The role of mast cells of the gingival mucosa in the pathogenesis of inflammatory periodontal diseases // Fundamental research. 2009. No. 7-S. P. 55-56 (In Russ.).

12. BASOv A.A., IVCHENKo L.G., DoMENYUK D.A., DMitrienko T.D., Nuzhnaya C.V. The role of oxidative stress in the pathogenesis of vascular complications in children with insulinable sugar diabetes. Archiv EuroMedica, 2019; 9(1): 136-145. https://doi. org/10.35630/2199-885X/2019/9/1/136

13. Davydov B.N., Domenyuk D.A., DMitrienko S.V. Peculiarities of microcirculation in periodont tissues in children of key age groups sufficient type 1 diabetes. Part I. Periodontology, 2019; Vol. 24; 1-24(90): 4-10. DOI: 10.25636/PMP.1.2019.1.1

14. Davydov B.N., Domenyuk D.A., DMitrienko S.V. Peculiarities of microcirculation in periodont tissues in children of key age groups sufficient type 1 diabetes. Part II. Periodontology, 2019; Vol. 24; 2-24(91): 108-119. DOI: 10.33925/1683-3759-2019-24-2-108-119
15. Domenyuk D.A., Porfyriadis M.P., BudayCHIEv G. M-A. Contemporary methodological approaches to diagnosing bone tissue disturbances in children with type 1 diabetes. Archiv EuroMedica, 2018; 8(2): 71-81.

16. Domenyuk D.A., SAMedov F., DMitrienko S.V., Anfinogenova O.I., Glizhova T.N., LysaN D., Nuzhnaya CH. Matrix metalloproteinases and their tissue inhibitors in the pathogenesis of periodontal diseases in type 1 diabetes mellitus // Archiv EuroMedica. 2019. Vol. 9. № 3. P. 81-90. https://doi. org/10.35630/2199-885X/2019/9/9/3.25 